\title{
Measurement of thyroglobulin level in lateral neck lymph node fine needle aspiration washout fluid in papillary thyroid cancer
}

\author{
Kwangsoon Kim^^, Ja Seong Bae^, Jeong Soo Kim^^ \\ Department of Surgery, College of Medicine, Catholic University of Korea, Seoul, Republic of Korea \\ Contributions: (I) Conception and design: K Kim, JS Kim; (II) Administrative support: JS Bae; (III) Provision of study materials or patients: K Kim, JS \\ Kim; (IV) Collection and assembly of data: K Kim, JS Kim; (V) Data analysis and interpretation: K Kim, JS Bae; (VI) Manuscript writing: All authors; \\ (VII) Final approval of manuscript: All authors. \\ Correspondence to: Professor Jeong Soo Kim, MD, PhD. Department of Surgery, College of Medicine, Catholic University of Korea, 06591 Seoul, \\ Republic of Korea. Email: btskim@catholic.ac.kr; Kwangsoon Kim, MD. Assistant professor, Department of Surgery, College of Medicine, Catholic \\ University of Korea, 06591 Seoul, Republic of Korea. Email: noar99@naver.com.
}

\begin{abstract}
Background: Thyroglobulin (Tg) level of fine needle aspiration (FNA) washout fluid (FNA-Tg) is useful to detect cervical lymph node (LN) metastasis in patients with papillary thyroid cancer (PTC). The objective of this study was to determine appropriate cutoff values of serum $\mathrm{Tg}(\mathrm{S}-\mathrm{Tg}$ ) and FNA-Tg levels for diagnosis of lateral neck LN metastasis and investigate their diagnostic performance.

Methods: A total of 169 patients with PTC who underwent modified radical neck dissection (mRND) were retrospectively reviewed at Seoul St. Mary's Hospital (Seoul, Korea) from December 2011 to September 2019. Diagnostic performance of FNA-Tg, Tg ratio (FNA-Tg level/S-Tg level), and FNA-Tg combined with $\mathrm{Tg}$ ratio was evaluated by correlation with FNA cytology results.

Results: FNA-Tg level $\geq 20 \mathrm{ng} / \mathrm{mL}$ exhibited $86.6 \%$ sensitivity, $66.7 \%$ specificity, and $81.7 \%$ accuracy. $\mathrm{Tg}$ ratio $\geq 3$ exhibited lower sensitivity but higher specificity (82.7\% and $73.8 \%$, respectively) than FNA-Tg level $\geq 20 \mathrm{ng} / \mathrm{mL}$. FNA-Tg level $\geq 20 \mathrm{ng} / \mathrm{mL}$ combined with $\mathrm{Tg}$ ratio $\geq 3$ had $81.9 \%$ sensitivity, $80.5 \%$ accuracy, and an integrated area under the curve (iAUC) of 0.790 .

Conclusions: Measurement of FNA-Tg level increases preoperative diagnostic accuracy for the detection of metastatic LNs in patients with PTC. Diagnostic accuracy is higher using a $20 \mathrm{ng} / \mathrm{mL} \mathrm{FNA-Tg} \mathrm{cutoff}$ level. $\mathrm{Tg}$ ratio is also valuable and FNA-Tg combined with $\mathrm{Tg}$ ratio shows promise.
\end{abstract}

Keywords: Thyroglobulin washout; fine needle aspiration (FNA); lymph node metastasis; papillary thyroid cancer (PTC); modified radical neck dissection (mRND)

Submitted Jun 02, 2021. Accepted for publication Jul 30, 2021.

doi: $10.21037 /$ gs-21-366

View this article at: https://dx.doi.org/10.21037/gs-21-366

\section{Introduction}

Papillary thyroid cancer (PTC) is the most common thyroid malignancy, accounting for $75-85 \%$ of all thyroid cancers. Its incidence has been significantly increasing worldwide over the last several decades (1-3). Although PTC has an excellent long-term prognosis due to its indolent features, up to $65 \%$ metastasize to the central compartment lymph nodes (LNs) (4-6), and metastases to the lateral neck LNs are observed in approximately $15 \%$ of patients at presentation and throughout long-term follow-up (7). Accurate diagnosis of LN metastasis, particularly those located in the lateral neck, is important to avoid unnecessary cervical neck dissection

\footnotetext{
^ ORCID: Kwangsoon Kim, 0000-0001-6403-6035; Ja Seong Bae, 0000-0002-6271-2105; Jeong Soo Kim, 0000-0002-9982-7838.
} 
when managing PTC patients. Neck ultrasonography (US) and US-guided fine needle aspiration (FNA) cytology are the standard diagnostic modalities used (8-10); however, USguided FNA cytology has variable sensitivity and specificity, depending on operator skill (11-13). In addition, adequate specimen acquisition is difficult in cases of highly vascular or cystic LN metastasis.

Recent studies have demonstrated that thyroglobulin (Tg) measurement from FNA washout fluid (FNA-Tg) is useful to detect cervical LN metastasis and has excellent diagnostic performance $(14,15)$. According to the American Thyroid Association (ATA) management guidelines, FNA cytology and FNA-Tg measurement should be performed for suspicious LNs found on US (8). However, controversy regarding the optimal FNA-Tg cutoff value remains due to many factors, including the wide range of FNA-Tg levels, presence of serum $\mathrm{Tg}$ antibodies (TgAb), different FNA techniques, and variation between the different Tg measurement assay kits available $(15,16)$. Grani et al. reported a $1.0 \mathrm{ng} / \mathrm{mL}$ FNA-Tg cutoff value but pointed out that better standardization of criteria for patient selection, $\mathrm{Tg}$ measurement methods, and cutoff values are needed (15).

Therefore, we aimed to determine appropriate cutoff values for serum $\mathrm{Tg}(\mathrm{S}-\mathrm{Tg})$ and FNA-Tg to diagnose PTC lateral neck $\mathrm{LN}$ metastasis and investigate their diagnostic performance.

We present the following article in accordance with STROBE reporting checklist (available at https://dx.doi. org/10.21037/gs-21-366).

\section{Methods}

\section{Patients}

We retrospectively reviewed the medical records of 185 PTC patients who underwent modified radical neck dissection (mRND) at Seoul St. Mary's Hospital (Seoul, Korea) from December 2011 to September 2019. Five patients were excluded due to inadequate data and 11 due to loss of follow-up. Finally, 169 patients were included for analysis. Patients with LNs suspicious for malignancy on US but negative FNA cytology underwent LN biopsy for intraoperative frozen section examination; $\mathrm{mRND}$ was performed if the suspicious LNs contained malignancy. The study was conducted in accordance with the Declaration of Helsinki (as revised in 2013). This study was approved by the institutional review board of Seoul St. Mary's Hospital and the Catholic University of Korea (IRB No:
KC20RISI0043), and the need for informed consent was waived due to the retrospective nature of this study.

\section{US and FNA cytology}

All patients underwent high-resolution neck US using 7-13 MHz high-frequency linear array transducers. Experienced radiologists evaluated all neck levels (IVI) bilaterally and performed US-guided FNA on LNs suspicious or indeterminate for metastasis, which were characterized by round shape, loss of fatty hilum, microcalcifications, cystic changes, hyperechogenicity, and peripheral vascular flow on color Doppler images (17).

US-guided FNA was performed with the needle oriented either parallel or perpendicular to the US probe using a 23-gauge needle connected to a $2-10 \mathrm{~mL}$ pistol-grip syringe. Tissue samples were collected with 6 or 7 "to-andfro" needle movements over 5-10 seconds and fixed in 95\% ethanol for Papanicolaou staining and cytologic examination. The slides were examined by experienced cytopathologists and reported as either nondiagnostic, benign, suspicious for malignancy, or malignancy. Nondiagnostic and benign results were considered negative; suspicious for malignancy and malignancy results were considered positive.

\section{Serum-Tg (S-Tg), TgAb and FNA-Tg analysis}

After FNA, the needle and syringe were washed with $1 \mathrm{~mL}$ of normal saline; the washout solution was collected and submitted to the laboratory for measurement of FNA-Tg. Patients also underwent venipuncture to collect a blood sample for measurement of S-Tg and TgAb. Both S-Tg and FNA-Tg were measured using an immunoradiometric Tg assay (CIS Bio International, Saclay, France) with a functional sensitivity of $0.2 \mathrm{ng} / \mathrm{mL}$. Serum $\mathrm{TgAb}$ concentration was measured using a radioimmunoassay (DIAsource, Rue du Bosquet, Belgium); serum TgAb level $<60 \mathrm{IU} / \mathrm{mL}$ was considered negative (16). The Tg ratio was defined as FNA-Tg level/S-Tg level (18).

\section{Preoperative US-guided needle localization}

On the morning of surgery, neck US was performed for all patients undergoing surgery to evaluate the neck LN status and to search for the target LNs. Experienced radiologists performed the procedures. The radiologist marked the location of the target LNs on the skin with an oil-based pen to facilitate US-guided needle localization with 21-gauge 
Table 1 Clinical characteristics of study patients

\begin{tabular}{|c|c|}
\hline Characteristics & Value \\
\hline Total patient number & 169 \\
\hline Age (years) & $42.9 \pm 13.6(12-79)$ \\
\hline$\geq 45$ & $70(41.4)$ \\
\hline$<45$ & $99(58.6)$ \\
\hline Male:female & $1: 2.3$ \\
\hline Male & $51(30.2)$ \\
\hline Female & $118(69.8)$ \\
\hline \multicolumn{2}{|l|}{ Extent of operation } \\
\hline TT with mRND & $149(88.2)$ \\
\hline Only mRND & $20(11.8)$ \\
\hline Tumor size (cm) & $1.5 \pm 0.9(0.3-5.0)$ \\
\hline Serum Tg (ng/mL) & $32.9 \pm 58.6(0.02-357.7)$ \\
\hline Serum TgAb (IU/mL) & $137.2 \pm 560.2(1.55-5,639.2)$ \\
\hline Negative & $132(78.1)$ \\
\hline Positive & 37 (21.9) \\
\hline FNA-Tg (ng/mL) & $573.9 \pm 527.4(0.00-2,853.8)$ \\
\hline \multicolumn{2}{|l|}{ FNA result } \\
\hline Negative for malignancy & $42(24.9)$ \\
\hline Positive for malignancy & $127(75.1)$ \\
\hline
\end{tabular}

Data are expressed as patient's number (\%), or mean \pm SD (range). Negative TgAb: TgAb $<60 \mathrm{IU} / \mathrm{mL}$; positive TgAb: TgAb $\geq 60 \mathrm{IU} / \mathrm{mL}$. Tumor size means the size of primary thyroid cancer. TT, total thyroidectomy; mRND, modified radical neck dissection; Tg, thyroglobulin; TgAb, thyroglobulin antibody; FNA, fine needle aspiration; FNA-Tg, Tg level of FNA washout fluid; SD, standard deviation.

hookwire. The tip of the needle was targeted to pass through the center of the LNs in real time.

\section{Postoperative management and follow-up}

Patients were managed after surgery according to the ATA management guidelines (8). All patients were administered suppressive doses of L-thyroxine and received regular followup with physical examination, thyroid function testing, measurement of serum TgAb level, and US of the neck every 3-6 months and annually thereafter. Postoperative radioactive iodine (RAI) ablation $(100-150 \mathrm{mCi})$ was performed 8-12 weeks after surgery; a diagnostic total body scan was performed 5-7 days after RAI ablation. If necessary, additional diagnostic imaging with computed tomography and/or positron emission tomography/computed tomography were performed.

\section{Statistical analysis}

Statistical analyses were performed using SPSS software version 24.0 for Windows (IBM Corp., Armonk, NY, USA). Continuous variables are presented as means with standard deviation; categorical variables are reported as numbers with percentages. Groups were compared using the Student's $t$-test, chi-square test, or Wilcoxon rank sum test. Receiver operating characteristics (ROC) curve analysis was performed to determine the optimal cutoff value for S-Tg, FNA$\mathrm{Tg}$, and $\mathrm{Tg}$ ratio by calculating the integrated area under the curve (iAUC). Patients were stratified into two groups according to the optimal cutoff value (low or high) for each measured or calculated variable. Diagnostic performance of FNA-Tg, Tg ratio, and combined FNA-Tg and Tg ratio was assessed by calculating sensitivity, specificity, negative predictive value, positive predictive value, and accuracy. All tests were two-sided. $\mathrm{P}<0.05$ was considered significant.

\section{Results}

\section{Patient characteristics}

Table 1 presents the clinical characteristics of the 169 study patients with PTC who underwent mRND. Mean age was $42.9 \pm 13.6$ years (range, $12-79$ years). Seventy patients $(41.4 \%)$ were $\geq 45$ years of age and $99(58.6 \%)$ were $<45$ years of age. Fifty patients $(30.2 \%)$ were male. A total of 149 (88.2\%) were newly diagnosed with PTC and underwent total thyroidectomy (TT) with mRND for lateral neck LN metastases; 20 (11.8\%) were patients with recurrent LN metastases diagnosed during follow-up after TT and underwent only mRND. Mean tumor size was $1.5 \pm 0.9 \mathrm{~cm}$ (range, $0.3-5.0 \mathrm{~cm}$ ). Mean S-Tg and FNA-Tg levels were $32.9 \pm 58.6$ and $573.9 \pm 527.4 \mathrm{ng} / \mathrm{mL}$, respectively. Serum TgAb was positive $(\geq 60 \mathrm{IU} / \mathrm{mL})$ in 37 patients $(21.9 \%)$. A total of 127 (75.1\%) were positive for malignancy and 42 (24.9\%) were negative for LN malignancy based on FNA cytology.

\section{Comparison of clinical characteristics according to FNA cytology result and $\mathrm{TgAb}$ status}

The comparison of clinical characteristics according to 
Table 2 Comparison of clinical characteristics according to FNA cytology result

\begin{tabular}{lccc}
\hline Characteristics & Negative $(\mathrm{n}=42)$ & Positive $(\mathrm{n}=127)$ & $\mathrm{P}$ value \\
\hline Age (years) & $43.1 \pm 15.1(12-79)$ & $42.9 \pm 13.2(15-73)$ & 0.946 \\
Female & $32(76.2)$ & $86(67.7)$ & 0.338 \\
Tumor size $(\mathrm{cm})$ & $1.4 \pm 0.8(0.3-3.7)$ & $1.6 \pm 0.9(0.4-5.0)$ & 0.165 \\
Serum Tg $(\mathrm{ng} / \mathrm{mL})$ & $34.3 \pm 67.5(0.32-357.7)$ & $32.5 \pm 55.6(0.02-283.1)$ & 0.866 \\
FNA-Tg $(\mathrm{ng} / \mathrm{mL})$ & $214.9 \pm 399.5(0.08-1,269.7)$ & $692.6 \pm 511.6(0.00-2,853.8)$ & 0.396 \\
Serum TgAb & & $97(76.4)$ \\
Negative & $35(83.3)$ & $30(23.6)$ \\
Positive & $7(16.7)$ & 0.01 & 0.05
\end{tabular}

Data are expressed as patient's number (\%), or mean $\pm \mathrm{SD}$ (range). A statistically significant difference was defined as $\mathrm{P}<0.05$. Negative TgAb: TgAb $<60 \mathrm{IU} / \mathrm{mL}$; positive TgAb: TgAb $\geq 60 \mathrm{IU} / \mathrm{mL}$. Tumor size means the size of primary thyroid cancer. Tg, thyroglobulin; TgAb, thyroglobulin antibody; FNA, fine needle aspiration; FNA-Tg, Tg level of FNA washout fluid; SD, standard deviation.

Table 3 Comparison of clinical characteristics according to serum TgAb status

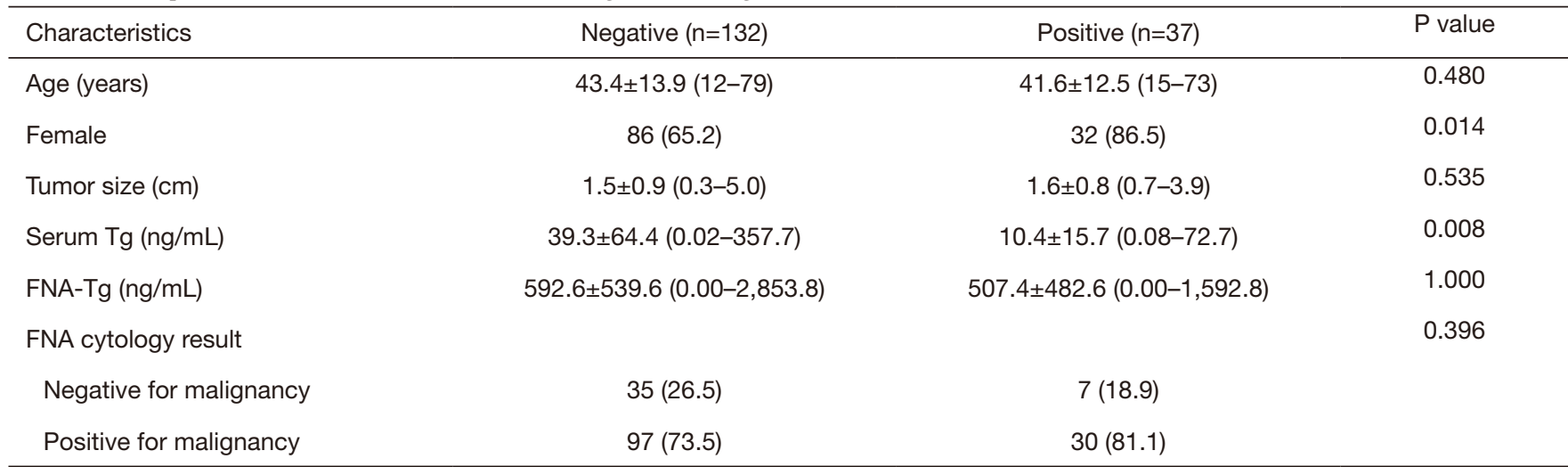

Data are expressed as patient's number (\%), or mean \pm SD (range). A statistically significant difference was defined as $P<0.05$. Negative TgAb: TgAb $<60 \mathrm{IU} / \mathrm{mL}$; positive TgAb: TgAb $\geq 60 \mathrm{IU} / \mathrm{mL}$. Tumor size means the size of primary thyroid cancer. Tg, thyroglobulin; TgAb, thyroglobulin antibody; FNA, fine needle aspiration; FNA-Tg, Tg level of FNA washout fluid; SD, standard deviation.

FNA cytology results are shown in Table 2. Mean age, gender, tumor size, S-Tg level, and serum TgAb status did not significantly differ between the negative and positive FNA cytology groups. However, mean FNA-Tg level was significantly higher in the positive group than the negative group (692.6 \pm 511.6 vs. $214.9 \pm 399.5 \mathrm{ng} / \mathrm{mL}, \mathrm{P}<0.001)$.

Table 3 presents the comparison of clinical characteristics according to serum TgAb status. The proportion of female patients was significantly higher in the positive serum $\mathrm{TgAb}$ group than the negative group $(86.5 \%$ vs. $65.2 \%, \mathrm{P}=0.014)$. $\mathrm{S}-\mathrm{Tg}$ level was significantly higher in the negative serum TgAb group $(39.3 \pm 64.4$ vs. $10.4 \pm 15.7 \mathrm{ng} / \mathrm{mL}, \mathrm{P}=0.008)$. There were no significant differences between the groups in mean age, tumor size, FNA-Tg level, or FNA cytology results.

\section{Comparison of clinical characteristics according to $\mathrm{S}-\mathrm{Tg}$ and FNA-Tg levels}

We evaluate the optimal cutoff value using the S-Tg and FNA-Tg levels from the ROC curve analysis. The patients were stratified into two groups according to S-Tg level: low S-Tg $(<1 \mathrm{ng} / \mathrm{mL}, \mathrm{n}=31,18.3 \%)$ and high S-Tg $(\geq 1 \mathrm{ng} / \mathrm{mL}$, $\mathrm{n}=138,81.7 \%)$. There were no significant differences between the groups except for serum TgAb status and FNA cytology results. The proportion of patients with positive FNA cytology results was significantly higher in the low S-Tg group (93.5\% vs. 71.0\%, $\mathrm{P}=0.010$ ) (Table 4).

Table 5 shows the comparison of clinical characteristics according to FNA-Tg level with the patients stratified into 
Table 4 Comparison of clinical characteristics in study patients stratified by serum Tg cutoff level of $1 \mathrm{ng} / \mathrm{mL}$

\begin{tabular}{|c|c|c|c|}
\hline Characteristics & Serum $\operatorname{Tg}<1 \mathrm{ng} / \mathrm{mL}(\mathrm{n}=31)$ & Serum $T g \geq 1 \mathrm{ng} / \mathrm{mL}(\mathrm{n}=138)$ & $P$ value \\
\hline Female & $22(70.1)$ & $96(69.6)$ & 0.878 \\
\hline Tumor size $(\mathrm{cm})$ & $1.5 \pm 0.6(0.6-3.2)$ & $1.5 \pm 0.9(0.3-5.0)$ & 0.714 \\
\hline FNA-Tg (ng/mL) & $630.5 \pm 480.5(0.15-1,708.2)$ & $547.7 \pm 535.5(0.00-2,853.8)$ & 0.174 \\
\hline Negative & $19(61.3)$ & $113(81.9)$ & \\
\hline Positive & $12(38.7)$ & $25(18.1)$ & \\
\hline FNA cytology result & & & 0.010 \\
\hline Negative for malignancy & $2(6.5)$ & $40(29.0)$ & \\
\hline
\end{tabular}

Data are expressed as patient's number (\%), or mean \pm SD (range). A statistically significant difference was defined as $\mathrm{P}<0.05$. Negative TgAb: TgAb <60 IU/mL; positive TgAb: TgAb $\geq 60 \mathrm{IU} / \mathrm{mL}$. Tumor size means the size of primary thyroid cancer. Tg, thyroglobulin; TgAb, thyroglobulin antibody; FNA, fine needle aspiration; FNA-Tg, Tg level of FNA washout fluid; SD, standard deviation.

Table 5 Comparison of clinical characteristics in study patients stratified by FNA-Tg cutoff level of $20 \mathrm{ng} / \mathrm{mL}$

\begin{tabular}{|c|c|c|c|}
\hline Characteristics & FNA-Tg $<20 \mathrm{ng} / \mathrm{mL}(\mathrm{n}=45)$ & FNA-Tg $\geq 20 \mathrm{ng} / \mathrm{mL}(\mathrm{n}=124)$ & $P$ value \\
\hline Female & $35(77.8)$ & $83(66.9)$ & 0.191 \\
\hline Tumor size $(\mathrm{cm})$ & $1.4 \pm 0.8(0.3-3.7)$ & $1.6 \pm 0.9(0.4-5.0)$ & 0.349 \\
\hline Serum Tg (ng/mL) & $29.7 \pm 62.3(0.08-357.7)$ & $34.2 \pm 57.4(0.02-283.1)$ & 0.658 \\
\hline Negative & $34(75.6)$ & $98(79.0)$ & \\
\hline Positive & $11(24.4)$ & $26(21.0)$ & \\
\hline FNA cytology result & & & $<0.001$ \\
\hline Negative for malignancy & $28(62.2)$ & $14(11.3)$ & \\
\hline
\end{tabular}

Data are expressed as patient's number (\%), or mean \pm SD (range). A statistically significant difference was defined as $\mathrm{P}<0.05$. Negative TgAb: TgAb <60 IU/mL; positive TgAb: TgAb $\geq 60 \mathrm{IU} / \mathrm{mL}$. Tumor size means the size of primary thyroid cancer. Tg, thyroglobulin; $\mathrm{TgAb}$, thyroglobulin antibody; FNA, fine needle aspiration; FNA-Tg, Tg level of FNA washout fluid; SD, standard deviation.

two groups: low FNA-Tg $(<20 \mathrm{ng} / \mathrm{mL}, \mathrm{n}=45,26.6 \%)$ and high FNA-Tg $(\geq 20 \mathrm{ng} / \mathrm{mL}, \mathrm{n}=124,73.4 \%)$. In contrast to the $\mathrm{S}$-Tg analysis, the proportion of patients with positive FNA cytology results was significantly higher in the high FNA-Tg group $(88.7 \%$ vs. $37.8 \%, \mathrm{P}<0.001)$.

\section{Comparison of clinical characteristics according to Tg ratio}

The comparison of clinical characteristics according to $\mathrm{Tg}$ ratio is summarized in Table 6. We evaluate the optimal cutoff value using the $\mathrm{Tg}$ ratio from the ROC curve analysis. Patients were stratified into two groups: low $\mathrm{Tg}$ ratio $(<3, \mathrm{n}=53,31.4 \%)$ and high $\mathrm{Tg}$ ratio $(\geq 3, \mathrm{n}=116$, $68.6 \%)$. There were no significant differences in mean age, gender, tumor size, or serum TgAb status between the groups. The proportion of patients with positive FNA cytology results was significantly higher in the high $\mathrm{Tg}$ ratio group $(90.5 \%$ vs. $41.5 \%, \mathrm{P}<0.001)$. 
Table 6 Comparison of clinical characteristics according to Tg ratio

\begin{tabular}{lccc}
\hline Characteristics & Tg ratio $<3(n=53)$ & Tg ratio $\geq 3(n=116)$ & $P$ value \\
\hline Age (years) & $41.6 \pm 15.8(12-79)$ & $43.6 \pm 12.5(15-73)$ & $77(66.4)$ \\
Female & $41(77.4)$ & $1.5 \pm 0.9(0.4-5.0)$ & 0.393 \\
Tumor size $(\mathrm{cm})$ & $1.6 \pm 1.0(0.3-5.0)$ & & 0.868 \\
Serum TgAb & & $91(78.4)$ \\
Negative & $41(77.4)$ & $25(21.6)$ \\
Positive & $12(22.6)$ & & 0.874 \\
FNA cytologic result & & $11(9.5)$ \\
Negative for malignancy & $31(58.5)$ & $105(90.5)$ \\
Positive for malignancy & $22(41.5)$ & $<0.001$ \\
\hline
\end{tabular}

Data are expressed as patient's number (\%), or mean \pm SD (range). A statistically significant difference was defined as $P<0.05$. Negative TgAb: TgAb <60 IU/mL; positive TgAb: TgAb $\geq 60 \mathrm{IU} / \mathrm{mL}$. Tumor size means the size of primary thyroid cancer. Tg ratio, FNA washout $\mathrm{Tg}$ level/serum Tg level; Tg, thyroglobulin; TgAb, thyroglobulin antibody; FNA, fine needle aspiration; SD, standard deviation.

Table 7 Diagnostic performance of different modalities used in the correlation with FNA cytology results

\begin{tabular}{|c|c|c|c|c|c|c|}
\hline Test & Sensitivity (\%) & Specificity (\%) & NPV (\%) & PPV (\%) & Accuracy (\%) & iAUC \\
\hline Tg ratio $\geq 3$ & 82.7 & 73.8 & 58.5 & 90.5 & 80.5 & 0.782 \\
\hline $\mathrm{S}-\mathrm{Tg}<1 \mathrm{ng} / \mathrm{mL}$ and FNA-Tg $\geq 20 \mathrm{ng} / \mathrm{mL}$ & 21.3 & 97.6 & 29.1 & 96.4 & 40.2 & 0.594 \\
\hline $\mathrm{S}-\mathrm{Tg}<1 \mathrm{ng} / \mathrm{mL}$ and $\mathrm{Tg}$ ratio $\geq 3$ & 22.0 & 97.6 & 29.3 & 96.6 & 40.8 & 0.598 \\
\hline
\end{tabular}

Tg, thyroglobulin; FNA, fine needle aspiration; FNA-Tg, Tg level of FNA washout fluid; NPV, negative predictive value; PPV, positive predictive value; iAUC, integrated area under the curve.

\section{Diagnostic performance of FNA-Tg, Tg ratio, and FNA- Tg combined with Tg ratio}

The diagnostic performance in the prediction of FNA cytology results with FNA-Tg, Tg ratio, and FNA-Tg combined with $\mathrm{Tg}$ ratio is shown in Table 7 . FNA- $\mathrm{Tg} \geq 20 \mathrm{ng} / \mathrm{mL}$ exhibited $86.6 \%$ sensitivity and $81.7 \%$ accuracy. Compared to FNA$\mathrm{Tg}$, Tg ratio $\geq 3$ had lower sensitivity ( $82.7 \%$ vs. $86.6 \%$ ), higher specificity $(73.8 \%$ vs. $66.7 \%)$, and higher iAUC $(0.782$ vs. 0.766). FNA-Tg combined with $\mathrm{Tg}$ ratio exhibited $81.9 \%$ sensitivity, $80.5 \%$ accuracy, and an iAUC of 0.790 .

\section{Discussion}

Preoperative assessment of cervical LN metastasis in patients with PTC determines the extent of surgery required for treatment. Neck US and US-guided FNA cytology are widely used methods for diagnosing primary thyroid lesions and LN metastasis (8-10). FNA cytology is highly accurate but produces false negative or nondiagnostic results in up to $20 \%$ of cystic, small, or highly vascular LNs (19-21).

Pacini et al. introduced Tg measurement from FNA washout fluid in 1992 for early detection of LN metastasis. Elevated FNA-Tg level indicated suspicion for metastasis, whereas an undetectable level indicated nondiagnostic or benign results (22). FNA-Tg measurement is an easily implemented method to increase diagnostic accuracy in suspicious LNs. Although several studies have demonstrated its usefulness, controversies remain regarding the optimal cutoff value, using different cutoff values based on thyroid or TgAb status, and others. Using 24 studies from 1975 to 2013, Grani et al. reported that FNA-Tg measurement had high accuracy in the early detection of cervical LN metastasis for differentiated thyroid carcinoma (DTC), but 
a better standardization of criteria for patient selection, and optimal cutoff values (15). Furthermore, Jeon et al. confirmed that FNA-Tg measurement was highly reliable in the diagnosis of cervical LN metastasis in patients with PTC, but high serum TgAb levels could interfere with FNA-Tg measurement (23). Various FNA-Tg cutoff values have been reported. That is because FNA-Tg levels are represented as a wide range in metastatic and nonmetastatic LNs and the different techniques of FNA$\mathrm{Tg}$ measurements were used with different functional sensitivities $(12,20,24-26)$. Snozek et al. suggested that FNA-Tg cutoff value of $1 \mathrm{ng} / \mathrm{mL}$ compared favorably with the cytopathology for the detection of PTC in cervical LNs (25). Kim et al. recommended that FNA-Tg cutoff value was $10 \mathrm{ng} / \mathrm{mL}$ to differentiate metastatic LNs (24). Although FNA-Tg measurement is usually helpful for detecting LN metastasis, the optimal cutoff value of FNA$\mathrm{Tg}$ is still been controversial.

The PTC patients in this study with malignant LN findings detected on preoperative FNA cytology underwent mRND upfront. Those with suspicious LNs on US but negative preoperative FNA cytology underwent intraoperative LN biopsy for frozen section histopathologic examination; mRND was performed if malignancy was detected. We attempted to improve the accuracy of preoperative diagnosis using FNA-Tg and S-Tg levels. FNA-Tg level $\geq 20 \mathrm{ng} / \mathrm{mL}$ had the best sensitivity (86.6\%) with $81.7 \%$ accuracy and correlated with FNA cytology results. Conversely, FNA-Tg level of $\geq 20 \mathrm{ng} / \mathrm{mL}$ indicated that negative preoperative FNA cytology could be a false negative result. Therefore, intraoperative frozen section biopsy of suspicious LNs with FNA-Tg level of $\geq 20 \mathrm{ng} / \mathrm{mL}$ might still be necessary. Tg ratio of $\geq 3$ showed slightly lower sensitivity but higher specificity and predictive accuracy than FNA-Tg level $\geq 20 \mathrm{ng} / \mathrm{mL}$. An FNA-Tg level of $\geq 20 \mathrm{ng} / \mathrm{mL}$ with $\mathrm{Tg}$ ratio of $>3$ suggests a considerable possibility of malignancy. The combination of FNA-Tg and $\mathrm{Tg}$ ratio showed the highest iAUC $(0.790)$ and had the best predictive accuracy. In case of FNA-Tg level of $\geq 20 \mathrm{ng} / \mathrm{mL}$ with $\mathrm{Tg}$ ratio of $\geq 3$ but negative preoperative FNA cytology, we have to consider the possibility of false negative of preoperative FNA cytology.

A previous study reported that S-Tg level does not predict the diagnosis of metastatic LNs in patients with PTC (16). Interestingly, our data showed that the proportion of patients with positive FNA cytology was significantly higher in patients with $\mathrm{S}-\mathrm{Tg}$ level $<1 \mathrm{ng} / \mathrm{mL}$ than those with $\mathrm{S}-\mathrm{Tg}$ level $\geq 1 \mathrm{ng} / \mathrm{mL}$ (93.5\% vs. $71.0 \%$,
$\mathrm{P}=0.010)$. This result was probably due to thyroiditis and $\mathrm{TgAb}$; the proportion of patients with positive serum $\mathrm{TgAb}$ was significantly higher in patients with $\mathrm{S}-\mathrm{Tg}$ level $<1 \mathrm{ng} / \mathrm{mL}$ ( $38.7 \%$ vs. $18.1 \%, \mathrm{P}=0.017)$. Korea is an iodinesufficient region, and iodine sufficiency is associated with thyroiditis (27). Therefore, patients with S-Tg level of $<1 \mathrm{ng} / \mathrm{mL}$ could be diagnosed as higher positive FNA cytology than patients with S-Tg level of $\geq 1 \mathrm{ng} / \mathrm{mL}$.

Preoperative neck US is commonly used to identify suspicious LNs (28-30). Suspicious findings for metastatic LNs include size enlargement, loss of fatty hilum, oval shape, hyperechogenicity, cystic composition, microcalcification, and peripheral vascularity. Hwang et al. reported that preoperative neck US had high sensitivity and specificity for predicting cervical LN metastasis in the lateral neck (28). We analyzed the results of a combination of various modalities with US features. The correlation of FNA cytology results with different modalities with US features is shown in Table S1. We expected better diagnostic performance when using US features with FNA-Tg and Tg ratio together. However, we found that diagnostic performance using US features together with FNA-Tg level and $\mathrm{Tg}$ ratio was rather low (sensitivity, 60.6\%; accuracy, 66.9\%).

This study has several limitations. It was retrospective in nature with a relatively small sample size and conducted in a single center. Thus, selection bias may have been introduced and our results may not be applicable to the general PTC patient population. In addition, FNA cytology and FNA$\mathrm{Tg}$ measurement were only performed in LNs suspicious for malignancy. Diagnostic accuracy would have been more clearly identified if all LNs were examined. Finally, we did not consider other factors that affect S-Tg and FNA$\mathrm{Tg}$ levels, such as thyroiditis and TgAb. The prevalence of Hashimoto's thyroiditis is high in Korea, which may have influenced the study results. A prospective or matched study that reflects the effect of Hashimoto's thyroiditis and TgAb would help to clarify their impact. Nonetheless, the most important strength of this study was that every patient was followed using a standardized protocol in a single institution, including S-Tg, FNA-Tg measurement and FNA cytology examination.

\section{Conclusions}

On the basis of the result from our study, FNA-Tg measurement increases preoperative diagnostic accuracy in detecting metastatic LNs in patients with PTC. Diagnostic accuracy is higher using a $20 \mathrm{ng} / \mathrm{mL}$ FNA-Tg cutoff level. 
$\mathrm{Tg}$ ratio is also valuable. FNA-Tg level combined with $\mathrm{Tg}$ ratio shows promise to improve preoperative diagnostic accuracy in the detection of metastatic LNs.

\section{Acknowledgments}

Funding: This research was supported by Basic Science Research Program through the National Research Foundation of Korea (NRF) funded by the Ministry of Education (NRF-2015R1D1A1A01058798).

\section{Footnote}

Reporting Checklist: The authors have completed the STROBE reporting checklist. Available at https://dx.doi. org/10.21037/gs-21-366

Data Sharing Statement: Available at https://dx.doi. org/10.21037/gs-21-366

Peer Review File: Available at https://dx.doi.org/10.21037/ gs-21-366

Conflicts of Interest: All authors have completed the ICMJE uniform disclosure form (available at https://dx.doi. org/10.21037/gs-21-366). The authors have no conflicts of interest to declare

Ethical Statement: The authors are accountable for all aspects of the work in ensuring that questions related to the accuracy or integrity of any part of the work are appropriately investigated and resolved. The study was conducted in accordance with the Declaration of Helsinki (as revised in 2013). The study was approved by Ethics Committee of the Institutional Review Board at Seoul St. Mary's Hospital and the Catholic University of Korea (IRB No: KC20RISI0043), and individual consent for this retrospective analysis was waived.

Open Access Statement: This is an Open Access article distributed in accordance with the Creative Commons Attribution-NonCommercial-NoDerivs 4.0 International License (CC BY-NC-ND 4.0), which permits the noncommercial replication and distribution of the article with the strict proviso that no changes or edits are made and the original work is properly cited (including links to both the formal publication through the relevant DOI and the license). See: https://creativecommons.org/licenses/by-nc-nd/4.0/.

\section{References}

1. Chen AY, Jemal A, Ward EM. Increasing incidence of differentiated thyroid cancer in the United States, 19882005. Cancer 2009;115:3801-7.

2. Cramer JD, Fu P, Harth KC, et al. Analysis of the rising incidence of thyroid cancer using the Surveillance, Epidemiology and End Results national cancer data registry. Surgery 2010;148:1147-52; discussion 1152-3.

3. Davies L, Welch HG. Increasing incidence of thyroid cancer in the United States, 1973-2002. JAMA 2006;295:2164-7.

4. Roh JL, Park JY, Park CI. Total thyroidectomy plus neck dissection in differentiated papillary thyroid carcinoma patients: pattern of nodal metastasis, morbidity, recurrence, and postoperative levels of serum parathyroid hormone. Ann Surg 2007;245:604-10.

5. Wada N, Duh QY, Sugino K, et al. Lymph node metastasis from 259 papillary thyroid microcarcinomas: frequency, pattern of occurrence and recurrence, and optimal strategy for neck dissection. Ann Surg 2003;237:399-407.

6. Hartl DM, Leboulleux S, Al Ghuzlan A, et al. Optimization of staging of the neck with prophylactic central and lateral neck dissection for papillary thyroid carcinoma. Ann Surg 2012;255:777-83.

7. Mulla MG, Knoefel WT, Gilbert J, et al. Lateral cervical lymph node metastases in papillary thyroid cancer: a systematic review of imaging-guided and prophylactic removal of the lateral compartment. Clin Endocrinol (Oxf) 2012;77:126-31.

8. Haugen BR, Alexander EK, Bible KC, et al. 2015 American Thyroid Association Management Guidelines for Adult Patients with Thyroid Nodules and Differentiated Thyroid Cancer: The American Thyroid Association Guidelines Task Force on Thyroid Nodules and Differentiated Thyroid Cancer. Thyroid 2016;26:1-133.

9. Boland GW, Lee MJ, Mueller PR, et al. Efficacy of sonographically guided biopsy of thyroid masses and cervical lymph nodes. AJR Am J Roentgenol 1993;161:1053-6.

10. Jeon SJ, Kim E, Park JS, et al. Diagnostic benefit of thyroglobulin measurement in fine-needle aspiration for diagnosing metastatic cervical lymph nodes from papillary thyroid cancer: correlations with US features. Korean J Radiol 2009;10:106-11.

11. Frasoldati A, Toschi E, Zini M, et al. Role of thyroglobulin measurement in fine-needle aspiration biopsies of cervical 
lymph nodes in patients with differentiated thyroid cancer. Thyroid 1999;9:105-11.

12. Baskin HJ. Detection of recurrent papillary thyroid carcinoma by thyroglobulin assessment in the needle washout after fine-needle aspiration of suspicious lymph nodes. Thyroid 2004;14:959-63.

13. Kessler A, Rappaport Y, Blank A, et al. Cystic appearance of cervical lymph nodes is characteristic of metastatic papillary thyroid carcinoma. J Clin Ultrasound 2003;31:21-5.

14. Moon JH, Kim YI, Lim JA, et al. Thyroglobulin in washout fluid from lymph node fine-needle aspiration biopsy in papillary thyroid cancer: large-scale validation of the cutoff value to determine malignancy and evaluation of discrepant results. J Clin Endocrinol Metab 2013;98:1061-8.

15. Grani G, Fumarola A. Thyroglobulin in lymph node fineneedle aspiration washout: a systematic review and metaanalysis of diagnostic accuracy. J Clin Endocrinol Metab 2014;99:1970-82.

16. Jeon MJ, Kim WG, Jang EK, et al. Thyroglobulin level in fine-needle aspirates for preoperative diagnosis of cervical lymph node metastasis in patients with papillary thyroid carcinoma: two different cutoff values according to serum thyroglobulin level. Thyroid 2015;25:410-6.

17. Kwak JY. Preoperative Staging of Well Differentiated Thyroid Cancer: US Is Enough? J Korean Thyroid Assoc 2011;4:18-21.

18. Chung J, Kim EK, Lim H, et al. Optimal indication of thyroglobulin measurement in fine-needle aspiration for detecting lateral metastatic lymph nodes in patients with papillary thyroid carcinoma. Head Neck 2014;36:795-801.

19. Cignarelli M, Ambrosi A, Marino A, et al. Diagnostic utility of thyroglobulin detection in fine-needle aspiration of cervical cystic metastatic lymph nodes from papillary thyroid cancer with negative cytology. Thyroid 2003;13:1163-7.

20. Cunha N, Rodrigues F, Curado F, et al. Thyroglobulin detection in fine-needle aspirates of cervical lymph nodes: a technique for the diagnosis of metastatic differentiated thyroid cancer. Eur J Endocrinol 2007;157:101-7.

Cite this article as: Kim K, Bae JS, Kim JS. Measurement of thyroglobulin level in lateral neck lymph node fine needle aspiration washout fluid in papillary thyroid cancer. Gland Surg 2021;10(9):2686-2694. doi: 10.21037/gs-21-366
21. Alexander EK, Heering JP, Benson CB, et al. Assessment of nondiagnostic ultrasound-guided fine needle aspirations of thyroid nodules. J Clin Endocrinol Metab 2002;87:4924-7.

22. Pacini F, Fugazzola L, Lippi F, et al. Detection of thyroglobulin in fine needle aspirates of nonthyroidal neck masses: a clue to the diagnosis of metastatic differentiated thyroid cancer. J Clin Endocrinol Metab 1992;74:1401-4.

23. Jeon MJ, Park JW, Han JM, et al. Serum antithyroglobulin antibodies interfere with thyroglobulin detection in fine-needle aspirates of metastatic neck nodes in papillary thyroid carcinoma. J Clin Endocrinol Metab 2013;98:153-60.

24. Kim MJ, Kim EK, Kim BM, et al. Thyroglobulin measurement in fine-needle aspirate washouts: the criteria for neck node dissection for patients with thyroid cancer. Clin Endocrinol (Oxf) 2009;70:145-51.

25. Snozek CL, Chambers EP, Reading CC, et al. Serum thyroglobulin, high-resolution ultrasound, and lymph node thyroglobulin in diagnosis of differentiated thyroid carcinoma nodal metastases. J Clin Endocrinol Metab 2007;92:4278-81.

26. Borel AL, Boizel R, Faure P, et al. Significance of low levels of thyroglobulin in fine needle aspirates from cervical lymph nodes of patients with a history of differentiated thyroid cancer. Eur J Endocrinol 2008;158:691-8.

27. Chung HR. Iodine and thyroid function. Ann Pediatr Endocrinol Metab 2014;19:8-12.

28. Hwang HS, Orloff LA. Efficacy of preoperative neck ultrasound in the detection of cervical lymph node metastasis from thyroid cancer. Laryngoscope 2011;121:487-91.

29. Kim E, Park JS, Son KR, et al. Preoperative diagnosis of cervical metastatic lymph nodes in papillary thyroid carcinoma: comparison of ultrasound, computed tomography, and combined ultrasound with computed tomography. Thyroid 2008;18:411-8.

30. Roh JL, Park JY, Kim JM, et al. Use of preoperative ultrasonography as guidance for neck dissection in patients with papillary thyroid carcinoma. J Surg Oncol 2009;99:28-31. 
Supplementary

Table S1 Diagnostic performance of different modalities with US features used in the correlation with FNA cytologic result

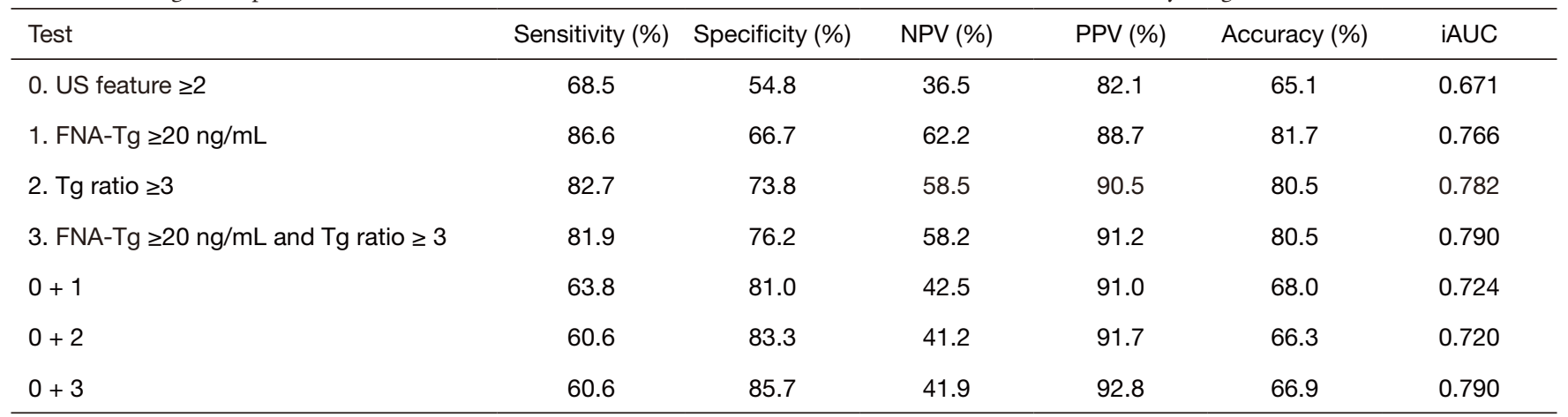

US features: size enlargement, loss of fatty hilum, oval shape, hyperechogenicity, cystic composition, microcalcification, peripheral vascularity. Tg, thyroglobulin; FNA, fine needle aspiration; FNA-Tg, Tg level of FNA washout fluid; NPV, negative predictive value; PPV, positive predictive value; iAUC, integrated area under the curve; US, ultrasonography. 